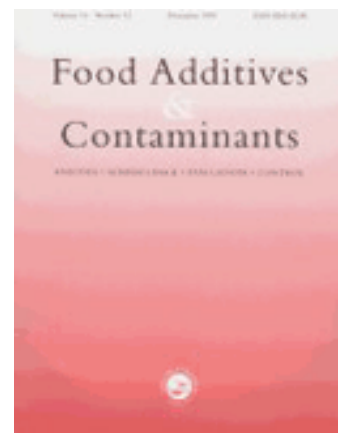

\title{
Absorption, distribution and elimination of fumonisin B1 metabolites in weaned piglets
}

\begin{tabular}{|c|c|}
\hline Journal: & Food Additives and Contaminants \\
\hline Manuscript ID: & TFAC-2006-380.R1 \\
\hline Manuscript Type: & Original Research Paper \\
\hline $\begin{array}{r}\text { Date Submitted by the } \\
\text { Author: }\end{array}$ & 07-Jun-2007 \\
\hline Complete List of Authors: & $\begin{array}{l}\text { Fodor, Judit; Research Group of Animal Breeding and Animal } \\
\text { Hygiene, University of Kaposvár, Faculty of Animal Science } \\
\text { Balogh, Krisztian; Szent István University, Department of Nutrition } \\
\text { Weber, Maria; Szent István University, Department of Nutrition } \\
\text { Mezes, Miklos; Szent István University, Department of Nutrition } \\
\text { Kametler, Laszlo; Research Group of Animal Breeding and Animal } \\
\text { Hygiene, University of Kaposvár, Faculty of Animal Science } \\
\text { Posa, Roland; Research Group of Animal Breeding and Animal } \\
\text { Hygiene, University of Kaposvár, Faculty of Animal Science } \\
\text { Mamet, Rene; Technische Universität München, Lehrstuhl für } \\
\text { Tierhygiene } \\
\text { Bauer, Johann; Technische Universität München, Lehrstuhl für } \\
\text { Tierhygiene } \\
\text { Horn, Peter; Research Group of Animal Breeding and Animal } \\
\text { Hygiene, University of Kaposvár, Faculty of Animal Science } \\
\text { Kovacs, Ferenc; Research Group of Animal Breeding and Animal } \\
\text { Hygiene, University of Kaposvár, Faculty of Animal Science } \\
\text { Kovacs, Melinda; Research Group of Animal Breeding and Animal } \\
\text { Hygiene, University of Kaposvár, Faculty of Animal Science }\end{array}$ \\
\hline Methods/Techniques: & Toxicology - in-vivo, Toxicology - metabolism \\
\hline Additives/Contaminants: & Fumonisins, Mycotoxins - fumonisins \\
\hline Food Types: & Animal products meat, Animal feed \\
\hline
\end{tabular}




\section{SCHOLARONE" \\ Manuscripts}




\section{Absorption, distribution and elimination of fumonisin $\mathbf{B}_{1}$ metabolites in 2 weaned piglets}

3

4

5 


\section{Introduction}

3 Fumonisins were first isolated in 1988 from a culture of Fusarium verticillioides (earlier

4 Fusarium moniliforme) strain MRC 826 grown on maize (Gelderblom et al. 1988, Cawood et 5 al. 1991), and subsequently their structure was also determined (Bezuidenhout et al. 1988). 6 The fumonisin $\mathrm{B}$ analogues, including toxicologically important $\mathrm{FB}_{1}, \mathrm{FB}_{2}$ and $\mathrm{FB}_{3}$ are the 7 most abundant naturally occurring fumonisins (Marasas, 1996). Fumonisin $\mathrm{B}_{1}\left(\mathrm{FB}_{1}\right)$ causes 8 leukoencephalomalacia in horses (Marasas et al. 1988) and pulmonary oedema in swine 9 (Harrison et al. 1990). It is carcinogenic and has been implicated in the pathogenesis of 10 oesophageal cancer in humans (Marasas et al. 1996).

12 The results of surveys indicate that fumonisins contaminate the maize kernels in all corn13 growing countries of the world and can cause fumonisin toxicosis (Dutton 1996). The exact 14 mechanism of action of $\mathrm{FB}_{1}$ has still not been elucidated. Fumonisins are very similar to 15 sphingolipids in molecular structure (Shier 1992); thus, they interfere in the metabolism of the 16 latter and disturb the processes mediated by these molecules (Kim et al. 1991).

Food materials of animal origin may become contaminated with $\mathrm{FB}_{1}$ after the toxin has been 19 absorbed from the digestive tract, entered the bloodstream and reached the peripheral tissues. 20 Therefore, from the food safety point of view it is especially important to know the 21 distribution of this mycotoxin in the organism. However, the toxin concentration detectable in 22 the organs, urine and faeces is influenced by the metabolism of the toxin to a large extent. 23 Only a few data have been so far reported in the literature about the metabolism of $\mathrm{FB}_{1}$ 24 (Marasas et al., 2000). 
1 The $\mathrm{FB}_{1}$ molecule includes a long chain aminopentol backbone $\left(\mathrm{AP}_{1}\right)$ with two ester-linked

2 tricarballylic acids (TCA). $\mathrm{AP}_{1}$ originates from $\mathrm{FB}_{1}$ by hydrolysis of the tricarballylic acid

3 side chains at carbon 14 and 15 , which are then replaced by hydroxyl groups. PHFB 1

4 (partially hydrolysed $\mathrm{FB}_{1}$ ) is a result of partial hydrolysis (Merrill et al., 1993).

5 Little is known about the possible endogenous hydrolysis of $\mathrm{FB}_{1}$ by the mammalian 6 metabolism, even if some studies performed on primates (Shepard et al. 1994) and ruminants 7 (Rice and Ross, 1994) revealed that the ester moiety of $\mathrm{FB}_{1}$ was hydrolyzed in the intestine.

9 In our earlier study (Fodor et al., 2006a), from the toxin intake (50 mg per animal per day or

$102.2 \mathrm{mg}$ per $\mathrm{kg}$ body weight per day) of five days, a mean value of $13 \%$ was excreted in urine 11 and faeces. Distribution of the excreted toxin in faeces and urine was $87 \%$ and $13 \%$, 12 respectively. Our examinations have applied to the unchanged chemical form of $\mathrm{FB}_{1}$ only. It 13 must be noted that the actual elimination would have presumably been much higher than that 14 if the metabolised chemical forms had also been taken into consideration. Accordingly, it was 15 supposed that the major part of the toxin was excreted in a partly or totally hydrolysed form. 16 In this experiment, absorption, distribution and elimination of fumonisin $\mathrm{B}_{1}$ and its 17 metabolites were determined in pigs that were fed a ration containing $45 \mathrm{mg} \mathrm{FB} \mathrm{kg}^{-1}$ during 1810 days.

\section{Materials and methods}

\section{Experimental design and animals}

21 Sixteen weaned barrows (Hungarian Large White) from the age of 8 weeks, weighing 12-14 $22 \mathrm{~kg}$, were used in the experiment. The piglets were weighed and then divided into two groups: 23 an experimental group $(n=10)$ and a control group $(n=6)$. The animals were placed in 24 metabolic cages for the trial. The room temperature $\left(20{ }^{\circ} \mathrm{C}\right)$ was controlled according to the 
1 needs of weaned piglets. Feed was given twice a day, in two equal portions, and the amount

2 of feed not consumed by the animals was measured. Drinking water was available ad libitum

3 via automatic drinkers. The experimental animals were fed a basal diet of a composition

4 corresponding to their age $\left(187 \mathrm{~g} \mathrm{~kg}^{-1}\right.$ crude protein, $12.8 \mathrm{MJ} \mathrm{kg}^{-1}$ metabolizable energy, 13.1

$5 \mathrm{~g} \mathrm{~kg}^{-1}$ lysine; ingredients: wheat $30 \%$, barley $20 \%$, corn $15 \%$, soy-bean $10 \%$, concentrate 6 15\%). A Fusarium verticillioides (MRC 826) fungal culture (1\%) and $\mathrm{Cr}_{2} \mathrm{O}_{3}(0.5 \%)$ was

7 mixed into the feed of experimental animals, so as to provide a Cr-labelled, fumonisin8 contaminated $\left(45 \mathrm{mg} / \mathrm{kg} \mathrm{FB}\right.$; $\left.8.6 \mathrm{mg} / \mathrm{kg} \mathrm{FB}_{2} ; 4.6 \mathrm{mg} / \mathrm{kg} \mathrm{FB}_{3}\right)$ feed. Fumonisins were 9 produced by a locally developed method and with the application of Fusarium verticillioides 10 strain MRC 826 (Fodor et al., 2006b). The homogenized fungal culture contained $\mathrm{FB}_{1}, \mathrm{FB}_{2}$ 11 and $\mathrm{FB}_{3}$ at a concentration of $5645 \mathrm{mg} \mathrm{kg}^{-1}, 1083 \mathrm{mg} \mathrm{kg}^{-1}$ and $581 \mathrm{mg} \mathrm{kg}^{-1}$, respectively.

12 After a five-day adaptation period, according to the method of Tossenberger et al. (2000), a 13 special T-cannula was implanted into the distal part of the ileum, before the ileocaecal valve, 14 in order to determine the absorption of $\mathrm{FB}_{1}$ from the feed marked by $\mathrm{Cr}_{2} \mathrm{O}_{3}$. At days 1 and 10 15 of the intoxication period, and 10 days after the withdrawal of the contaminated diet animals 16 were weighed and blood samples were taken. From the blood samples lipid peroxidation 17 parameters were measured, as a complementary examination. From the beginning of the 18 experiment to end, total quantity of urine and faeces was collected, in order to determine the 19 toxin content of them. At the end of both of periods, piglets $(n=5$ treated and 3 control 20 animals) were killed by bleeding after sedation. Gross pathological examinations were 21 performed, organs were weighed and several organs were sampled, in order to determine their 22 toxin content and lipid peroxidation status.

24 The experiments were carried out according to the regulations of the Hungarian Animal 25 Protection Act. The allowance number for the studies was MÁB-11/2002; KÁ-16/2001. 
2 Determination of mycotoxin content in feeds and fungal cultures

3 The mycotoxin content of the control and the experimental feed was checked. T-2 mycotoxin

4 was determined with GC-MS (LOD: $0.01 \mathrm{mg} \mathrm{kg}^{-1}$ ), while zearalenone (LOD: $0.01 \mathrm{mg} \mathrm{kg}^{-1}$ ),

5 DON (LOD: $0.05 \mathrm{mg} \mathrm{kg}^{-1}$ ) and ochratoxin A (LOD: $0.1 \mu \mathrm{g} \mathrm{kg}^{-1}$ ) by a HPLC system.

6

7 The determination of $\mathrm{FB}_{1}, \mathrm{FB}_{2}$ and $\mathrm{FB}_{3}$ content from the culture and feed samples was

8 confirmed also by a HPLC fluorescence detection method based upon derivatisation with o-

9 phthaldialdehyde (OPA), as described earlier (Fodor et al., 2006a).

10

11 The diet fed to the control group did not contain detectable amounts of mycotoxin.

12

13 Lipid peroxidation examinations

14 For the determination of lipid peroxidation, the samples of blood and organs were stored at $1582{ }^{\circ} \mathrm{C}$ until analysis. Lipid peroxidation was determined by the quantification of 16 malondialdehyde (MDA) levels with 2-thiobarbituric acid method in blood plasma (Placer et 17 al., 1966), liver, lung, brain, kidney and spleen (Mihara et al., 1980). Among the small 18 molecular weight antioxidants, the amount of reduced glutathione (Sedlak and Lindsay, 1968) 19 was measured in blood plasma, and red blood cell haemolysate and in the above-mentioned 20 organs.

Determination of fumonisin absorption and excretion

23 For the investigation of absorption of $\mathrm{FB}_{1}$, weaned barrows implanted with a special T24 cannula (PVTC) into the distal part of the ileum were used. The operation was carried out 7 25 days before toxin feeding. In the intoxication period (for 10 days) chymus samples were 
1 collected twice a day (2-3 hrs after feed consumption) from every animal. Based on the rate of

$2 \quad \mathrm{FB}_{1}$ and $\mathrm{Cr}_{2} \mathrm{O}_{3}$ in the feed, the absorption degree of the fumonisin was quantifiable from the

3 chymus toxin content. In the experimental diet the concentration of $\mathrm{Cr}$ and $\mathrm{FB}_{1}$ was $3.84 \mathrm{~g} \mathrm{~kg}^{-}$

$4{ }^{1}$ and $45 \mathrm{mg} \mathrm{kg}^{-1}$, respectively. During the calculation of $\mathrm{FB}_{1}$ absorption (as calculated from 5 the $\mathrm{Cr}-\mathrm{FB}_{1}$ ratio in the feed) the $85: 1$ of $\mathrm{Cr}: \mathrm{FB}_{1}$ ratio was taken as a basis. Therefore, the 6 absorption was calculated (\%) based on deviation from the rate of 85:1.

7

8 The preparation of the samples was carried out by the method of Christian and Coup (1954),

9 and for the determination of the chymus $\mathrm{Cr}$ content atomabsorption method (Atomabsorption Spectrophotometer, AA-6701F Shimadzu) was used. For the atomizing, acetylene-air flame was applied. From day 2, during the calculation it was corrected with the toxin amount excreted back into the intestine by bile (literature data; Dantzer et al., 1999; biliary excretion of $\mathrm{FB}_{1}: 1.4 \%$ of the dose at $4 \mathrm{~h}$ after dosing). It was also taken the recovery rate of $\mathrm{Cr}$ (at the end of the ileum; Cr recovery: 98.6\%; Köhler, 1993) into consideration.

In order to monitor the excretion of fumonisins, during the trial the total quantity of urine and faeces was collected. Faeces were collected two times daily (following the morning and afternoon feeding), and weighed with gram precision. Every day the entire quantity of faeces (stored at $4{ }^{\circ} \mathrm{C}$ until further processing) was homogenised and $10 \mathrm{~g}$ was sampled and frozen (at $-18{ }^{\circ} \mathrm{C}$ ) until laboratory analysis. Urine was collected continuously into a sealed container connected, and its volume was measured following the morning feeding. The urine collected daily was homogenised and $100 \mathrm{ml}$ was stored at $-18^{\circ} \mathrm{C}$ until the analysis. 
1 The amount of toxins detectable in different organs and tissues including the liver, lungs,

2 kidney, brain, spleen, the $m$. longissimus dorsi and $m$. psoas major muscles, and abdominal

3 and subcutaneous fat was determined. Furthermore, the toxin content of faecal, urine and

4 chymus samples was measured.

5

6 Quantification and identification of intact fumonisin $B_{1}$ and fumonisin $B_{2}$ and metabolites of

$7 \quad \mathrm{FB}_{1}$, namely aminopentol and partially hydrolysed fumonisin $\mathrm{B}_{1}$ was carried out using LC

8 (PerkinElmer, Series 200; USA)-MS (API 3200 LC/MS/MS System; Applied Biosystems,

9 USA). In the absence of analytic standard for $\mathrm{FB}_{2}$ metabolites, the absorption of $\mathrm{FB}_{2}$ was not

10 determined. The determination of tissues' and urines toxin content is equal of the described in 11 the method of Fodor et al. (2006a).

13 Non-dried and non-lyophilized faeces ( $2 \mathrm{~g}$ ) and chymus (5 g) samples were extracted by a 14 mixture of $0.1 \mathrm{M}$ ethylenediaminetetraacetate (EDTA) and methanol $(8 \mathrm{ml} ; 3 / 1 \mathrm{v} / \mathrm{v})$ for 60 15 min. The samples were filtrated through a fiberglass filter (Whatman GF A, Dassel, Germany) 16 after centrifugation ( $2000 \mathrm{~g} ; 3 \mathrm{~min}$ ). An aliquot of the filtrate was analysed.

18 Similarly to our earlier experiment (Fodor et al., 2006a), pure $\mathrm{FB}_{1}$ and $\mathrm{FB}_{2}$ (Sigma, 19 Schnelldorf, Germany) were used for the determination. PHFB 1 (partially hydrolysed $\mathrm{FB}_{1}$ ) 20 standard was prepared by Stephen M. Poling (U.S.A.), according to the method of Poling and 21 Plattner (1999). This standard was an equilibrium mixture of the two partially hydrolyzed $\mathrm{FB}_{1}$ 22 forms. ( $\mathrm{PHFB}_{1} \mathrm{a}-\mathrm{TCA}$ group at the C-15 hydroxy group (hydrolysis at C-14); $\mathrm{PHFB}_{1} \mathrm{~b}-\mathrm{TCA}$ 23 group at the $\mathrm{C}-14$ (i.e. hydrolysis at $\mathrm{C} 15)$ ). $\mathrm{AP}_{1}$ standard for the analysis was made by the 
1 method of Pagliuca et al. (2005). Every standard was diluted with a mixture of $\mathrm{ACN} / \mathrm{H}_{2} \mathrm{O}$

2 (1:1). Table 1 shows the validation data for the $\mathrm{FB}_{1}$ and its metabolites, and $\mathrm{FB}_{2}$.

4 Taking the low feed concentrations of $\mathrm{FB}_{3}$ into account, as compared to the other $\mathrm{FB}$ forms,

5 and its presence supposedly under the LOD value, these parameters were not aimed to

6 determine.

$7 \quad$ [Insert Table 1 about here]

9 Determination of $F B_{1}$ conversion into metabolites

10 Based on the molecular weights of the fumonisin $B_{1}$ compounds (fumonisin $B_{1}(\alpha)$ : 721 $11 \mathrm{~g} / \mathrm{mol}$; aminopentol $(\beta): 405 \mathrm{~g} / \mathrm{mol}$; aminopolyols $(\gamma): 563 \mathrm{~g} / \mathrm{mol}$ ) $\mathrm{FB}_{1}$ conversion into its 12 metabolites was calculated, as described below:

14 the fumonisin $\mathrm{B}_{1}-$ aminopentol conversion:

$15 \lambda \alpha \rightarrow \beta=\frac{m \beta / M \beta}{m \alpha / M \alpha}=\frac{m \beta}{m \alpha} \times \frac{M \alpha}{M \beta}$

16 the fumonisin $\mathrm{B}_{1}$ - partially hydrolyzed $\mathrm{FB}_{1}$ conversion:

$17 \lambda \alpha \rightarrow \gamma=\frac{m \gamma / M \gamma}{m \alpha / M \alpha}=\frac{m \gamma}{m \alpha} \times \frac{M \alpha}{M \gamma}$

18 where $m$ indicates the mass of compounds in $1 \mathrm{~g}$ and $M$ means their relative molecular 19 weights.

21 Statistical analysis

22 The entire measurement dataset was analysed statistically. Correlation analysis $(\mathrm{P} \leq 0.05)$ was 23 performed to determine the correlation between the concentration of $\mathrm{FB}_{1}$ and $\mathrm{PHFB}_{1}$ or $\mathrm{AP}_{1}$ 24 in the faeces samples. Data processing and the mathematical-statistical calculations were 
1 performed using the Correlate and Descriptive Statistics modules of the SPSS 10.0

2 programme package and the spreadsheet and figure editor programmes of EXCEL 7.0.

3 Statistical evaluation of the results derived from blood sampling was carried out by analysis

4 of variance (ANOVA) and least significant difference (LSD) "post hoc" tests.

\section{$5 \quad$ Results and Discussion}

6 Clinical signs and findings of the pathomorphological examinations

7 Pigs consumed $36.6 \pm 6.5 \mathrm{mg} \mathrm{FB}_{1}$ per day did not show clinical signs of disease and their feed

8 consumption was balanced throughout the experiment. At the first examination (after the 10-

9 day long toxin exposure) pulmonary oedema, the typical disease entity caused by fumonisin-

10 contaminated feed, developed in all of the piglets $(n=5)$ as a result of the toxin dose applied.

11 In the pleural cavity of animals a small volume $(2-7 \mathrm{ml})$ of slightly yellowish fluid with 12 clotting characteristics could be found. Of the other organs examined, beside the pathological 13 change of the liver, the heart, and the kidneys, the spleen showed hyperplasia. 10 days after 14 the end of the toxin feeding, in case of 4 animals $8-9 \mathrm{ml}$ fluid was distinctly visible in the 15 pericardium. The pulmonary oedema was estimated as minor degree.

\section{Antioxidant results}

18 Based on results of the lipid peroxidation measures, it could be concluded that the glutathione 19 content of blood plasma and haemolysed red blood cell was decreased significantly (Figure 1) 20 but other changes indicative of lipid peroxidation were found neither in the period of toxin 21 exposure nor after that time. In the concentration of reduced glutathione a significant $22(\mathrm{P}=0.0007)$ decrease was experienced between the first and second sampling in case of treated 23 group (Figure 1), while in the control group this value remained at an identical level with the 
1 first blood sampling. Similar decrease $(\mathrm{P}=0.043)$ was found in GSH levels/concentration

2 between these two time points in the RBC haemolysates.

3 [Insert Figure 1 about here]

4 Summarized, fumonisin in the applied dose did not cause the production of peroxyl radicals in

5 significant measure in these tissues but in bood (plasma and haemolysed RBC) it resulted 6 reduction in the second line of the antioxidant system, namely in the reduced glutathione. This

7 hypothesis is supported by the findings that fumonisin $B_{1}$ induces oxidative stress in human, 8 rat and mouse neural cell cultures. Decreased GSH levels, indicative of lipid peroxidation and 9 necrotic cell death were observed in all cell lines after incubation with $\mathrm{FB}_{1}$ (Stockmann et al., 10 2004).

11 Our results provide the first evidence that the fumonisins in vivo appear to decrease the GSH 12 content in blood and haemolysed RBC, associated with lipid peroxidation.

14 Absorption of fumonisin $B_{1}$

15 Table 2 shows the results of the calculated daily absorption (per animal) of $\mathrm{FB}_{1}$ in the 10-day 16 period. By eighty individual data (taking the molecular weight of $\mathrm{FB}_{1}, \mathrm{PHFB}_{1}$ and $\mathrm{AP}_{1}$ into 17 account) it was established that the mean accumulative absorption rate of all animals tested 18 for intact fumonisin $\mathrm{B}_{1}$ and its metabolites formed in the small intestine (till the end of the 19 ileum) is $4 \%$. There was no significant correlation between the daily fumonisin intake and the 20 absorption of the toxin. Until now, about the exact absorption of $\mathrm{FB}_{1}$ only computed data 21 were available; this is the first result from an absorption measurement.

22 [Insert Table 2 about here]

23 Following gavage dosing to vervet monkeys, only small amounts of $\mathrm{FB}_{1}$ were absorbed, and 24 after $24 \mathrm{hr}$ major organs retained little of the radiolabel, with the liver retaining the most 25 (Shephard et al., 1995). The p.o bioavailability of $\mathrm{FB}_{1}$ was $3.5 \%$ after single doses of $10 \mathrm{mg}$ 
$1 \quad \mathrm{FB}_{1} \mathrm{~kg}^{-1}$ to rats, estimated by serial blood, liver and kidney tissue samples (Martinez-

2 Larranaga et al., 1999). Based on plasma and excretion data of pigs, systematic bioavailability

3 following intragastrical dosing was estimated to be higher, as compared to the above

4 mentioned, approximately 3-6 \% (Prelusky et al., 1994).

5 In the chymus, the $\mathrm{FB}_{1}$ conversion into aminopentol and partially hydrolysed $\mathrm{FB}_{1}$ was $1 \%$ and

$63.9 \%$, respectively (data not shown). Accordingly, the biotransformation (metabolism) of

7 fumonisin $B_{1}$ was proven to happen already in the small intestine; the absorption of

8 metabolites (mainly of the aminopentol) might also occur.

9 No data have so far been reported on the $\mathrm{FB}_{1}$ metabolite of small intestinal content. In the 10 experiment of Shephard et al (1995), at the time of sacrifice, the stomachs and small intestines 11 of the monkeys were empty, so the scheme of chymus sampling was not successful. All bile 12 samples failed to show the presence of any hydrolysis products in the cited study. Based on 13 this fact, Shephard et al. supposed already in 1995 that the hydrolysis process occurs only in 14 the gut and not in the liver.

\section{Fumonisin content of the organs examined}

17 With respect to the toxin content of organs, much lower $\mathrm{FB}_{1}$ concentrations (maximum level 18 in the liver) were measured, as compared to those in our earlier experiment (Fodor et al., 19 2006a). This was probably due to the difference between the daily feed intake (in the earlier 20 trial 2 and at present $2.2 \mathrm{mg} \mathrm{kg}^{-1}$ bw.) and the length (for 22 and 10 days, respectively) of the 21 toxin load in the two trials.

22 [Insert Table 3 about here]

23 In the investigated tissues $50 \%$ of the recovered $\mathrm{FB}_{1}$ was intact (Table 3 ). $\mathrm{FB}_{1}$ conversion into 24 aminopentol and partially hydrolysed $\mathrm{FB}_{1}$ was $30 \%$ and $20 \%$, respectively. In most of the 
1 organs detectable amounts of $\mathrm{FB}_{1}(50 \%)$ and its metabolite, aminopentol (50\%) were

2 measured even 10 days after the dosage of the non-contaminated feed.

$4 \quad$ Excretion of fumonisins

5 During the 10-day toxin-feeding period, the daily toxin intake of the animals was $36.6 \pm 6.5$

$6 \mathrm{mg}\left(2.2 \mathrm{mg} \mathrm{kg}^{-1}\right.$ bw. $)$ in average. In the first five days after begining of the toxin feeding, the

$7 \quad \mathrm{FB}_{1}$ concentration of the faecal content increased continuously, and then from the $5^{\text {th }}$ day to

8 the $10^{\text {th }}$ day it was about $55 \mu \mathrm{g} \mathrm{g}^{-1}$ (Figure 2). There was no change in the aminopentol

9 concentration after the $3^{\text {rd }}$ day, it was measured in standard but low $\left(6 \mu \mathrm{g} \mathrm{g}^{-1}\right)$ concentration.

10 [Insert Figure 2 about here]

11 Taking the molecular weight of the compounds into account, it was established that during the 12 continuous toxin exposure (in 10 days) $59 \%$ of the total fumonisin $\mathrm{B}_{1}$ compounds recovered 13 in the faeces were determined as partially (47\%) or totally (12\%) hydrolysed metabolites.

14 Previous toxicokinetic studies on vervet monkeys, based on iv and oral dosing of $\mathrm{FB}_{1}$, 15 similarly demonstrated the rapid elimination of $\mathrm{FB}_{1}$ in the faeces (Shephard et al., 1995). The 16 extent of hydrolysis varied considerably, although the main product was the partially 17 hydrolysed form (approximately $1 / 3$ of total fumonisins), with very small recovered amounts 18 of the fully hydrolysed (aminopentol) moiety.

20 Investigating the period between the $5^{\text {th }}$ and $10^{\text {th }}$ day, and having regard to all fumonisins, $2172 \%(27.3 \mathrm{mg})$ of $\mathrm{FB}_{1}$ taken up was recovered daily in the faeces. Between the days 5 and 10 , 22 a slower but constant increase was noted in the daily-excreted amount, suggesting a balance 23 between the $\mathrm{FB}_{1}$ intake and its elimination. 
1 During the time of toxin exposure a relatively close correlation $(r=-0.4, \mathrm{P}<0.05)$ was found

2 between the concentration of $\mathrm{FB}_{1}$ and $\mathrm{PHFB}_{1}$ in the faeces samples, while there was no

3 statistically significant correlation between the concentration of $\mathrm{FB}_{1}$ and $\mathrm{AP}_{1}$.

4

5 After changing the experimental feed for the non-contaminated, a significant decrease was

6 observed in the concentration of $\mathrm{FB}_{1}$ and its metabolites already on the $3^{\text {rd }}$ day. Three days

7 after the end of toxin feeding, $\mathrm{PHFB}_{1}$ was the dominant compound (75\%) in the faeces. Less

8 than $1 \mathrm{mg}$ fumonisins were excreted daily after the $15^{\text {th }}$ day via faeces. Detectable amounts of

$9 \quad \mathrm{FB}_{1}$ and its metabolites were measured in the faeces even 10 days after the dosage of the non10 contaminated feed.

$1223 \%$ of the $\mathrm{FB}_{2}$ consumed during the trial was eliminated by the faeces. This value is much 13 lower than in the results of Shephard and Snijman. (1999), where the recoveries of 14 unmetabolized $\mathrm{FB}_{2}$ from faeces of 2 vervet monkeys were $8 \%$ and $56 \%$ (mean: $32 \%$ ) over a 15 7-day period. This paper also addresses the occurrence of partially hydrolysed $\mathrm{FB}_{2}$, which 16 accounts for some of the remainder of the dose.

$181.5 \%$ of $\mathrm{FB}_{1}$ quantity taken up was excreted with the urine during the entire trial, about $65 \%$ 19 in original, $16 \%$ in totally hydrolysed and $24 \%$ in partially hydrolysed form, while $0.6 \%$ of 20 the $\mathrm{FB}_{2}$ consumed during the trial was eliminated via urine, as intact molecule.

22 Summarized, from the $360 \mathrm{mg} \mathrm{FB}_{1}$ taken up in 10 days, $247.5 \mathrm{mg}$ (69\%) $\mathrm{FB}_{1}$ (plus 23 metabolites) was excreted by the faeces and urine during the toxin load and the 10-day long 24 elimination period. In the first 10 days $222 \mathrm{mg}$ (90\%), while after this time $25.5 \mathrm{mg}(10 \%)$ 25 fumonisins were recovered. 


\section{Conclusion}

3 In our first in vivo experiment (Fodor et al., 2006a) on the toxin elimination, by the

4 determination of the intact $\mathrm{FB}_{1}$ moieties, a strongly negative balance was found in the total 5 toxin amount, when taking the moieties excreted in the urine and faeces into account. This 6 was, at least in part, the basis of the present experiment, where the most important and 7 frequent metabolites were also determined.

9 From the trials on animals, we could draw a conclusion that the intestinal microbiota of pigs 10 is able to transform the intact $\mathrm{FB}_{1}$ to a similarly toxic substance (partially hydrolysed $\mathrm{FB}_{1}$ ) or 11 a more toxic metabolite (aminopentol). As a general principle, from the two metabolites, 12 partially hydrolysed $\mathrm{FB}_{1}$ has priority during the metabolic process. The conversion of $\mathrm{FB}_{1}$ to $13 \mathrm{AP}_{1}$ is notable even despite of its little amount, because this new compound means a new risk 14 from the viewpoint of animal- and human health as well, taking into account that aminopentol 15 is hydrophobic molecule (with a more effective absorption) and that its further derivative (N16 palmitoyl-aminopentol) appears to be tenfold toxic than the original $\mathrm{FB}_{1}$ (Humpf et al., 1998). 17 On the basis of the calculated accumulative absorption rate (maximally 4\%) it is not clear, which metabolites shaped exactly this value. From the point of view of human exposure, 19 special attention should be paid to $\mathrm{AP}_{1}$ appeared in edible tissues even 10 days after the 20 dosage of the non-contaminated feed because there is a lack of information about the effect of 21 this metabolite consumed in low concentration but for a long term.

$23 \mathrm{AP}_{1}$ was less potent than $\mathrm{FB}_{1}$ as an inhibitor of ceramide synthase in vitro (Merrill et al., 24 1993). A feeding study in which rats were fed corn containing $50 \mathrm{ppm}$ of $\mathrm{FB}_{1}$ or $10 \mathrm{ppm} \mathrm{AP}_{1}$ 25 resulted in roughly equal toxicity signs in both groups, indicating that $\mathrm{AP}_{1}$ could be more 
1 toxic than $\mathrm{FB}_{1}$ itself (Hendrich et al. 1993). $\mathrm{AP}_{1}$ shows also cancer-promoting activity in liver

2 (Hendrich et al. 1993). Removing the tricarballylic acids, $\mathrm{AP}_{1}$ becomes not only an inhibitor

3 but also a substrate for acylation by ceramide synthase. In the presence of palmitoyl-CoA AP

4 is also acylated to form N-palmitoyl- $\mathrm{AP}_{1}\left(\mathrm{PAP}_{1}\right)$, which is a more potent inhibitor of 5 ceramide synthase (Humpf et al. 1998). Thus, if $\mathrm{FB}_{1}$ is efficiently metabolized to 6 aminopentol, the above mechanism may lead to metabolic activation.

7

8 Further investigations are reasoned to clarify the dose-dependent metabolism and absorption 9 of fumonisin $\mathrm{B}_{1}$.

\section{Acknowledgements}

12 This research was supported by the Office of Supported Research Institutions of the 13 Hungarian Academy of Sciences (project no. B04074), the Ministry of Education (NKFP 14 4/034/2001) and by the Hungarian Scholarship Board (HSB) and Deutscher Akademischer 15 Austausch Dienst (DAAD) project (HSB-DAAD 2006/7/4). The authors wish to thank Dr. 16 Stephen M. Poling (U.S.A.) for providing the partially hydrolysed fumonisin $\mathrm{B}_{1}$ standard. We 17 thank Dr. András Szabó (University of Kaposvár, Hungary) for professional advice.

\section{References}

19 Bezuidenhout, S. C., Gelderblom, W. C. A., Gorstallman, C. P., Horak, R. M., 20 Marasas, WFO, Spiteller, G. and VleggaAr, R., 1988, Structure elucidation of the 21 fumonisin mycotoxins from Fusarium moniliforme. Journal of the Chemical Society, 22 Chemical Communications, 11, 743-745. 
1 Cawood, M.E., Gelderblom, W.C.A., Vleggaar, R., Behrend, Y., Thiel, P.G. and MARASAW, W.F.O., 1991, Isolation of the fumonisin mycotoxins: a quantitative approach. Journal of Agricultural and Food Chemistry, 39, 1958-1962.

Christian, K. R., and M. R. Coup., 1954, Measurement of feed intake by grazing cattle and sheep. VI. The determination of chromic oxide in faeces. N.Z. J. Sci. Technol. 36:328.

DANTZER WR, Hopper J, Mullin K, Hendrich S, and Murphy PA., 1999, Excretion of (14)C-fumonizin B(1), (14)C-hydrolyzed fumonizin B(1), and (14)C-fumonizin B(1)fructose in rats. J Agric Food Chem. 47(10):4291-6.

DutTON, M.F., 1996, Fumonisins, mycotoxins of increasing importance: their nature and their effects. Pharmacology and Therapeutics, 70, 137-161.

Fodor J., K. Meyer, M. Riedlberger, J. Bauer, Horn P., Kovács F., and Kovács M., 2006a, Distribution and elimination of fumonisin analogues in weaned piglets after oral administration of Fusarium verticillioides fungal culture. Food Additives and Contaminants, 23(5):492-501.

Fodor, J., KAMETLER, L., and KovÁCs, M., 2006b, Practical aspects of fumonisin production under laboratory conditions. Mycotoxin Research. 2006. 22:211-216.

Gelderblom, W.C.A., Jaskiewicz, K., Marasas, W.F.O., Thiel, P.G., HoraK, R.M., VlegGAAR, R. and KRIEK, N.P.J., 1988, Fumonisins - novel mycotoxins with cancerpromoting activity produced by Fusarium moniliforme. Applied and Environmental Microbiology, 54, 1806-1811.

Harrison, L.R., Colvin, B.M., Greene, J.T., Newman, L.E. and Cole, J.R., 1990, Pulmonary edema and hydrothorax in swine produced by fumonisin-B1, a toxic metabolite of Fusarium moniliforme. Journal of Veterinary Diagnostic Investigation, 2, 217-221. 
1 Hendrich, S., Miller, K. A., Wilson, T. M., and Murphy, P. A., 1993, Toxicity of Fusarium

2

3

4 5 proliferatum-fermented nixtamalized corn-based diets fed to rats: Effect of nutritional status. J. Agric. Food Chem. 41: 1649-1654.

Humpf, H.-U., Schmelz, E.-M., Meredith, F.I., Vesper, H., VAles, T.R., Menaldino, D.S., LiotTA, D.C., and MERRILL, A.H. JR., 1998, Acylation of naturally occurring and synthetic 1-deoxysphinganines by ceramide synthase: formation of N-palmitoylaminopentol (PAP1) produces a toxic metabolite of hydrolyzed fumonizin (AP1), and a new category of ceramide synthase inhibitor. J. Biol. Chem., 273: 19060-19064 .

KIM, M.Y., LinARDIC, C., OBEID, L. and HANNUN, Y., 1991, Identification of sphingomyelin turnover as an effector mechanism for the action of tumor-necrosis-factor-alpha and gamma-interferon - specific role in cell-differentation. Journal of Biological Chemistry, 266, 484-489.

KÖHLER,T. 1993. Evaluation of techniques to collect ileal digesta in pigs. Ph.D.thesis of Anim. Nutr. Dept. Wageningen Agric. Univ.

Marasas, W.F.O., Kellerman, T.S., Gelderblom, W.C.A., Coetzer, J.A.W., Thiel, P.G. and VAN DER LUGT, J.J., 1988, Leukoencephalomalacia in a horse induced by fumonisin B1 isolated from Fusarium moniliforme. Onderstepoort. Journal of Veterinary Research, 55, 197-203.

MARASAS, W. F. O., 1996, Fumonisins: history, worldwide occurrence and impact, p. 1-17. In L. S. Jackson, J. W. DeVries, and L. B. Bullerman (ed.), Fumonisins in food. Plenum Press, New York, N.Y.

Marasas, W. F. O., Miller, J. D., Riley, R. T., Visconti, A. (eds). 2000. Fumonizin B , $_{1}$ International Programme on Chemical Safety (IPCS, UNEP, ILO, and WHO). Environmental Health Criteria 219 (Geneva: WHO) 
1 Marasas, W. F. O., Miller, J. D., Riley, R. T., and Visconti, A. (EDS), 2000, Fumonisin B1,

2 International Programme on Chemical Safety (IPCS, UNEP, ILO, and WHO). Environmental Health Criteria 219 (Geneva: WHO)

Martinez-Larranaga, M.R., Anadon, A., Diaz, M.J., FernandeZ-CruZ, M.L., Martinez, M.A., Frejo, M.T., Martinez, M., Fernandez, R., Anton, R.M., Morales, M.E. TAFUR, M. 1999. Toxicokinetic and oral bioavailability of fumonisin B1. Vet. Hum. Toxicol. 41:357-362.

Merrill A. H. JR., WANG E., GILChrist D. G., and RILEY R. T., 1993, Fumonisins and other inhibitors of de novo sphingolipid biosynthesis. Adv. Lipid Res. 26:215-234

Mihara, M., Uchiyama, M. AND FuKuZAwA, K., 1980, Thiobarbituric acid value of fresh homogenate of rat as parameter of lipid peroxidation in ageing, $\mathrm{CCl} 4$ intoxication and vitamin E deficiency. Biochemical Medicine 23 (5), 302-311.

Pagliuca G, Zironi E, Ceccolini A, Matera R, Serrazanetti GP, and Piva A., 2005, Simple method for the simultaneous isolation and determination of fumonisin B1 and its metabolite aminopentol-1 in swine liver by liquid chromatography--fluorescence detection. J Chromatogr B Analyt Technol Biomed Life Sci. 5;819(1):97-103.

Placer, Z.A., Cushman, L.L., Johnson, B.C., 1966, Estimation of product of lipid peroxidation (malonyl dialdehyde) in biochemical systems. Analytical Biochemistry $16(3), 359-364$.

Poling, S.M. and PlatTneR, R.D., 1999, Rapid purification of fumonisins and their hydrolysis products with solid-phase extraction columns. J. Agric. Food Chem. 47:2344-2349.

Prelusky, D.B., Trenholm, H.L. and Savard, M.E., 1994, Pharmacokinetic fate of 14Clabelled fumonisin-B1 in swine. Natural Toxins, 2, 73-80. 
1 RiCE LG, and Ross PF., 1994, Methods for detection and quantitation of fumonizins in corn,

2

3

4

5

6

7

8

9

10 cereal products and animal excreta. J Food Prot, 57: 536-540.

SEDLAK, I., LINDSAY, R.H., 1968, Estimation of total, protein-bound and non-protein sulfhydryl groups in tissues with Ellmann's reagent. Analytical Biochemistry 25 (2), 192-205.

Shephard GS, Thiel PG, Sydenham EW, VleggaAr R, and Alberts JF., 1994, Determination of the mycotoxin fumonizin B1 and identification of its partially hydrolysed metabolites in the faeces of non-human primates. Food Chem Toxicol, 32: 23-29.

ShePhARD GS, ThIEl PG, Sydenham EW, and SAVARD ME., 1995, Fate of a single dose of [14C]-labelled fumonizin B1 in vervet monkeys. Nat Toxins, 3: 145-150.

ShEPhARD, G.S., SniJMAn, P.W. 1999. Elimination and excretion of a single dose of the mycotoxin fumonizin $\mathrm{B}_{2}$ in a non-human primate. Food Chem. Toxicol. 37:111-116.

SHIER, W.T., 1992, Sphingosine analogues: an emerging new classof toxins that includes the fumonisins. Journal of Toxicology - Toxin Reviews, 11, 241-257.

SPSS for Windows, ver. 10.0., 1999, SPSS Inc., Chicago, IL, USA

Stockmann-J. H., Mikkola J, NaArala J, Loikkanen J, ElovaARa E, Savolainen K., 2004, Fumonisin B1-induced toxicity and oxidative damage in U-118MG glioblastoma cells. Toxicology. 202(3):173-83.

Tossenberger J., FÉBel H., Babinszky L., Gundel J., Halas V., and Bódisné Garbacz Z. 2000, Ileal digestibility of amino acids in pigs. $1^{\text {st }}$ paper: Determination of ileal digestibility with different methods. (Review) (in Hungarian, with English abstract). Állattenyésztés és takarmányozás. 49.375-384. 


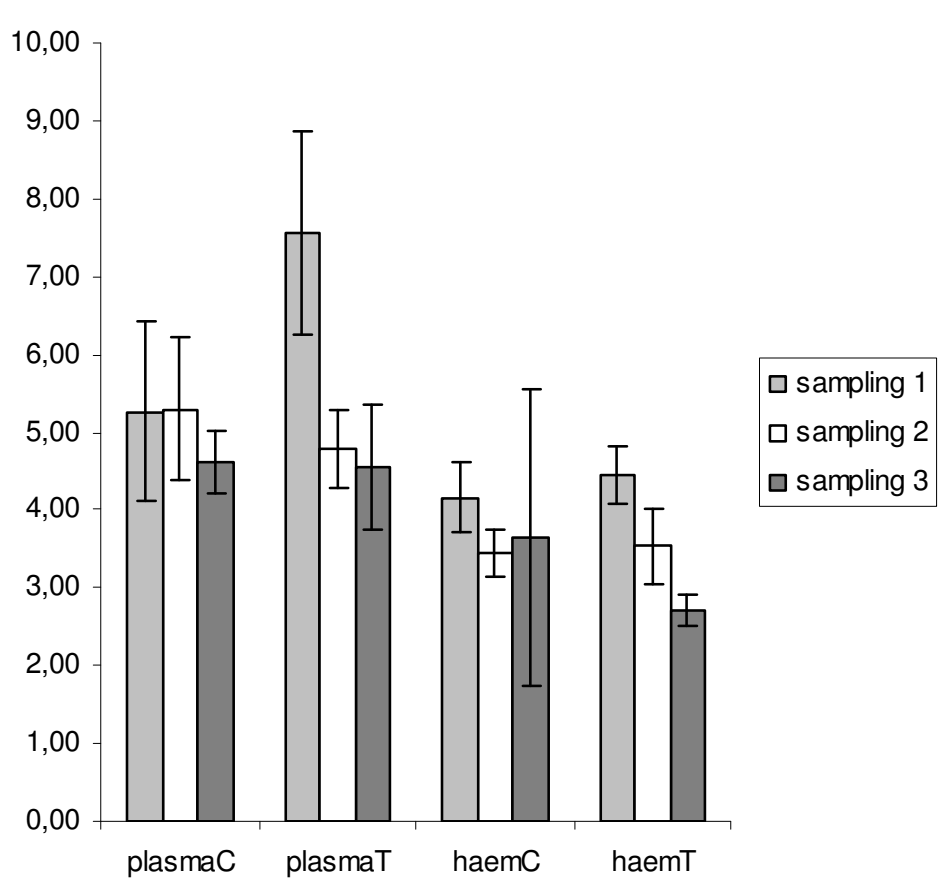

Figure 1. The amount of reduced glutathione (GSH) in blood plasma (plasma) and red blood cell haemolysate (haem) samples $(\mathrm{C}=$ contol group; $\mathrm{T}=$ group fed contaminated feed)

Sampling 1: at the beginning of the intoxication period (day 1); Sampling 2: at the end of the intoxication period (day 10); Sampling 3: 10 days after withdrawal the contaminated feed (day 20)

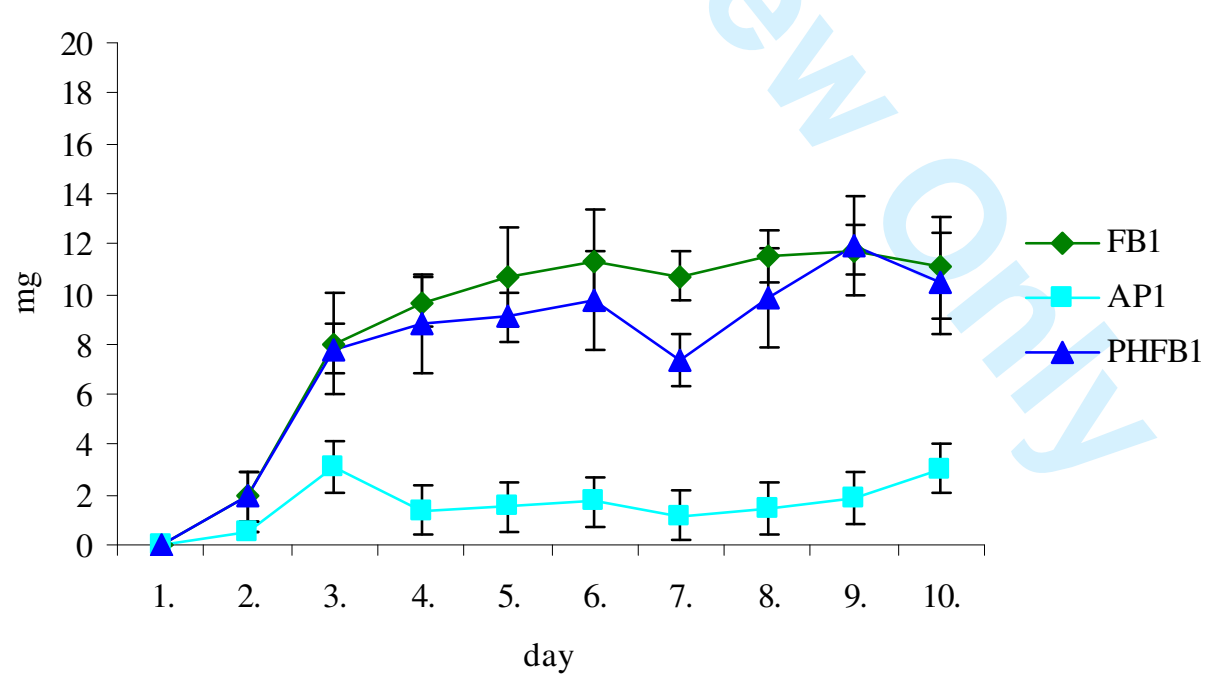

Figure 2. Amount of fumonisins (mg) recovered in faeces during the 10-day long exposure (mean \pm S.E.; $\mathrm{n}=10)$ 
Table 1. Validation data of the analysis

\begin{tabular}{|c|c|c|c|c|}
\hline Sample & & $\begin{array}{c}\text { Recovery } \\
\pm \mathrm{SD}^{\mathrm{a}}(\%)(\mathrm{n}=5) \\
\end{array}$ & $\begin{array}{c}\mathrm{LOQ}^{\mathrm{b}} \\
\left(\mu \mathrm{g} \mathrm{kg}^{-1}\right)(\mathrm{n}=5)\end{array}$ & $\begin{array}{c}\mathrm{LOD}^{\mathrm{c}} \\
\left(\mu \mathrm{g} \mathrm{kg}^{-1}\right)(\mathrm{n}=5)\end{array}$ \\
\hline \multirow{4}{*}{ Faeces, chymus } & $\mathrm{FB}_{1}$ & $140.0 \pm 14.7$ & 100 & 38.6 \\
\hline & $\mathrm{FB}_{2}$ & $107.2 \pm 11.7$ & 1000 & 155.1 \\
\hline & $\mathrm{AP}_{1}$ & $123.9 \pm 19.2$ & 100 & 56.0 \\
\hline & $\mathrm{PHFB}_{1}$ & $106.3 \pm 16.2$ & 100 & 35.6 \\
\hline \multirow{4}{*}{ Urine } & $\mathrm{FB}_{1}$ & $98.2 \pm 11.0$ & 10 & 1.2 \\
\hline & $\mathrm{FB}_{2}$ & $101.3 \pm 9.3$ & 10 & 3.6 \\
\hline & $\mathrm{AP}_{1}$ & $104.7 \pm 14.0$ & 10 & 1.9 \\
\hline & $\mathrm{PHFB}_{1}$ & $101.7 \pm 11.8$ & 10 & 1.2 \\
\hline \multirow{4}{*}{ Lung } & $\mathrm{FB}_{1}$ & $92.1 \pm 4.2$ & 10 & 1.4 \\
\hline & $\mathrm{FB}_{2}$ & $84.1 \pm 12.5$ & 10 & 2.2 \\
\hline & $\mathrm{AP}_{1}$ & $98.1 \pm 9.1$ & 10 & 1.3 \\
\hline & $\mathrm{PHFB}_{1}$ & $67.9 \pm 13.3$ & 10 & 0.9 \\
\hline \multirow{4}{*}{ Liver } & $\mathrm{FB}_{1}$ & $90.3 \pm 3.9$ & 10 & 1.2 \\
\hline & $\mathrm{FB}_{2}$ & $44.1 \pm 2.5$ & 10 & 2.1 \\
\hline & $\mathrm{AP}_{1}$ & $93.6 \pm 19.6$ & 10 & 1.4 \\
\hline & $\mathrm{PHFB}_{1}$ & $47.9 \pm 6.0$ & 10 & 0.8 \\
\hline \multirow{4}{*}{ Kidney } & $\mathrm{FB}_{1}$ & $60.3 \pm 13.3$ & 1 & 0.9 \\
\hline & $\mathrm{FB}_{2}$ & $54.7 \pm 1.4$ & 10 & 1.4 \\
\hline & $\mathrm{AP}_{1}$ & $115.2 \pm 8.2$ & 1 & 0.8 \\
\hline & $\mathrm{PHFB}_{1}$ & $47.2 \pm 5.7$ & 1 & 0.8 \\
\hline \multirow{4}{*}{ Spleen } & $\mathrm{FB}_{1}$ & $90.2 \pm 4.7$ & 10 & 1.0 \\
\hline & $\mathrm{FB}_{2}$ & $72.2 \pm 3.7$ & 10 & 1.3 \\
\hline & $\mathrm{AP}_{1}$ & $86.7 \pm 8.0$ & 1 & 0.7 \\
\hline & $\mathrm{PHFB}_{1}$ & $65.7 \pm 5.0$ & 1 & 0.5 \\
\hline \multirow{4}{*}{ Brain } & $\mathrm{FB}_{1}$ & $92.6 \pm 12.6$ & 1 & 0.6 \\
\hline & $\mathrm{FB}_{2}$ & $91.08 \pm 6.8$ & 10 & 2.3 \\
\hline & $\mathrm{AP}_{1}$ & $97.1 \pm 15.9$ & 1 & 0.8 \\
\hline & $\mathrm{PHFB}_{1}$ & $69.9 \pm 10.2$ & 1 & 0.4 \\
\hline \multirow{4}{*}{$\begin{array}{l}\text { Muscle (m.l.d., } \\
\text { m.p.m.) }\end{array}$} & $\mathrm{FB}_{1}$ & $87.5 \pm 11.0$ & 10 & 0.6 \\
\hline & $\mathrm{FB}_{2}$ & $60.4 \pm 7.2$ & 10 & 1.2 \\
\hline & $\mathrm{AP}_{1}$ & $91.3 \pm 8.6$ & 10 & 0.6 \\
\hline & $\mathrm{PHFB}_{1}$ & $84.3 \pm 15.0$ & 10 & 0.4 \\
\hline \multirow{4}{*}{$\begin{array}{l}\text { Fat (subcutaneous, } \\
\text { abdominal) }\end{array}$} & $\mathrm{FB}_{1}$ & $84.4 \pm 4.2$ & 1 & 0.7 \\
\hline & $\mathrm{FB}_{2}$ & $35.1 \pm 2.7$ & 100 & 3.9 \\
\hline & $\mathrm{AP}_{1}$ & $109.0 \pm 20.1$ & 1 & 0.6 \\
\hline & $\mathrm{PHFB}_{1}$ & $89.2 \pm 19.9$ & 1 & 0.6 \\
\hline
\end{tabular}

http://mc.manuscriptcentral.com/tfac Email: fac@tandf.co.uk 
Table 2. Accumulative absorption of the fumonisin $\mathrm{B}_{1}$ compounds 
Table 3. The concentration of the different $\mathrm{FB}_{1}$ derivatives in the organs and the conversion of the $\mathrm{FB}_{1}$ molecule into metabolites

\begin{tabular}{|c|c|c|c|c|c|c|c|}
\hline \multirow{3}{*}{\multicolumn{2}{|c|}{ Organs/Tissues }} & \multicolumn{6}{|c|}{$\begin{array}{l}\left.\text { Fumonisins' concentration (mean } \pm \mathrm{SE} ; \mu \mathrm{g} \mathrm{kg}^{-1}\right)^{*} \text { and the } \mathrm{FB}_{1} \\
\text { conversion }(\%) \text { into the separate metabolite }\end{array}$} \\
\hline & & \multicolumn{3}{|c|}{ Sampling $1(n=5)$} & \multicolumn{3}{|c|}{ Sampling $2(n=5)$} \\
\hline & & mean & $\pm \mathrm{SE}$ & $\%$ & mean & $\pm \mathrm{SE}$ & $\%$ \\
\hline \multirow{4}{*}{ Lung } & $\mathrm{FB}_{1}$ & 4.59 & 1.9 & & 0.93 & 0.1 & \\
\hline & $\mathrm{AP}_{1}$ & 0.56 & 1.1 & 17.0 & 0.31 & $0.28^{1}$ & 37.5 \\
\hline & $\mathrm{PHFB}_{1}$ & 0.25 & $0.2^{3}$ & 5.4 & $\mathrm{ND}^{5}$ & - & \\
\hline & $\mathrm{FB}_{2}$ & 0.53 & $0.4^{4}$ & & $\mathrm{ND}^{5}$ & - & \\
\hline \multirow{4}{*}{ Liver } & $\mathrm{FB}_{1}$ & 17.4 & 1.7 & & 8.25 & 0.5 & \\
\hline & $\mathrm{AP}_{1}$ & 0.38 & $0.7^{3}$ & 3.1 & 0.16 & $0.2^{3}$ & 3.3 \\
\hline & $\mathrm{PHFB}_{1}$ & 2.45 & $1.0^{3}$ & 14.9 & $\mathrm{ND}^{5}$ & - & \\
\hline & $\mathrm{FB}_{2}$ & 0.86 & $0.2^{2}$ & & $\mathrm{ND}^{5}$ & - & \\
\hline \multirow{4}{*}{ Kidney } & $\mathrm{FB}_{1}$ & 9.95 & 0.3 & & 3.62 & 0.1 & \\
\hline & $\mathrm{AP}_{1}$ & 7.53 & 3.2 & 53.1 & 2.1 & 0.9 & 51.0 \\
\hline & $\mathrm{PHFB}_{1}$ & 1.5 & 0.04 & 7.6 & $\mathrm{ND}^{5}$ & - & \\
\hline & $\mathrm{FB}_{2}$ & 0.53 & $0.24^{2}$ & & 0.34 & $0.2^{2}$ & \\
\hline \multirow{4}{*}{ Brain } & $\mathrm{FB}_{1}$ & 0.2 & $0.2^{2}$ & & $\mathrm{ND}^{5}$ & - & \\
\hline & $\mathrm{AP}_{1}$ & 0.57 & $0.4^{2}$ & 83.6 & 0.25 & $0.1^{1}$ & \\
\hline & $\mathrm{PHFB}_{1}$ & $\mathrm{ND}^{5}$ & - & & $\mathrm{ND}^{5}$ & - & \\
\hline & $\mathrm{FB}_{2}$ & $\mathrm{ND}^{5}$ & - & & $\mathrm{ND}^{5}$ & - & \\
\hline \multirow{4}{*}{ Sleep } & $\mathrm{FB}_{1}$ & 4.2 & 0.5 & & 0.41 & $0.1^{2}$ & \\
\hline & $\mathrm{AP}_{1}$ & 1 & 0.3 & 23.3 & 0.18 & $0.04^{3}$ & 41.2 \\
\hline & $\mathrm{PHFB}_{1}$ & 0.55 & 0.05 & 9.2 & 0.04 & $0.0^{2}$ & 6.6 \\
\hline & $\mathrm{FB}_{2}$ & 0.27 & 0.1 & & $\mathrm{ND}^{5}$ & - & \\
\hline \multirow{4}{*}{$\begin{array}{l}\text { M. longissi- } \\
\text { mus dorsi }\end{array}$} & $\mathrm{FB}_{1}$ & 11.2 & 1.2 & & 0.95 & $0.2^{2}$ & \\
\hline & $\mathrm{AP}_{1}$ & 0.72 & $0.3^{1}$ & 5.4 & 0.03 & $0.02^{2}$ & 5.3 \\
\hline & $\mathrm{PHFB}_{1}$ & 8.8 & 1.8 & 47.7 & $\mathrm{ND}^{5}$ & - & \\
\hline & $\mathrm{FB}_{2}$ & 7.9 & 1.3 & & 0.23 & $0.1^{3}$ & \\
\hline \multirow{4}{*}{$\begin{array}{l}\text { M. psoas } \\
\text { Major }\end{array}$} & $\mathrm{FB}_{1}$ & 4.75 & 1.5 & & 1.41 & 0.1 & \\
\hline & $\mathrm{AP}_{1}$ & 0.35 & 0.1 & 7.9 & 2.59 & 1.5 & 76.7 \\
\hline & $\mathrm{PHFB}_{1}$ & 1.92 & $0.3^{2}$ & 31.0 & $\mathrm{ND}^{5}$ & - & \\
\hline & $\mathrm{FB}_{2}$ & 4.06 & $1.4^{1}$ & & 0.28 & $0.1^{4}$ & \\
\hline \multirow{4}{*}{ Abdominal fat } & $\mathrm{FB}_{1}$ & 1.2 & 0.2 & & 0.9 & 0.13 & \\
\hline & $\mathrm{AP}_{1}$ & 5.6 & 3.2 & 76.1 & 3.6 & 0.7 & 80.6 \\
\hline & $\mathrm{PHFB}_{1}$ & 1.5 & 0.8 & 14.7 & 0.5 & 0.1 & 8 \\
\hline & $\mathrm{FB}_{2}$ & $\mathrm{ND}^{5}$ & - & & $\mathrm{ND}^{5}$ & - & \\
\hline \multirow{4}{*}{ Subcutaneous fat } & $\mathrm{FB}_{1}$ & 2.58 & 0.7 & & 0.3 & $0.1^{2}$ & \\
\hline & $\mathrm{AP}_{1}$ & 0.47 & $0.3^{3}$ & 17.2 & 0.1 & $0.1^{2}$ & 37.5 \\
\hline & $\mathrm{PHFB}_{1}$ & 1.12 & $0.8^{3}$ & 29.7 & $\mathrm{ND}^{5}$ & - & \\
\hline & $\mathrm{FB}_{2}$ & 0.3 & $0.3^{2}$ & & $\mathrm{ND}^{5}$ & - & \\
\hline
\end{tabular}

* superscripts indicate the number of samples in which toxin was not detected

ND not detected

SE standard error

sampling 1. immediately after the 10-day long toxin exposure

sampling 2. 10 days after withdrawal the contaminated feed 
